\title{
RUPTURE OF AN AORTIC ANEURYSM INTO THE PULMONARY ARTERY
}

BY

\section{G. H. JENNINGS}

From the Edgware General Hospital

Since ligation of a patent ductus arteriosus is now a popular and effective operation, it is of practical interest to consider other cardiac conditions that, by producing a similar murmur, may lead to a pre-operative error in diagnosis. If the " mill-wheel" or " machinery" murmur of patent ductus arteriosus has not fully developed, the error may be one of oversight, but confusion may also arise when a similar murmur is produced by other defects. These defects all include a free leak from the aorta above the cusps, and may be either congenital or acquired. If the defect be one in the aortic septum, the murmur may date from birth, and in such a case the expectation of life is not above fourteen years (Dadds and Hoyle, 1949). A similar murmur may follow rupture of a congenital aneurysm of the sinus of Valsalva into the pulmonary conus and may occur at twelve years or not until the patient is over forty years of age (Morgan Jones and Langley, 1949). These authors also described similar rupture of two acquired sinus aneurysms, one possibly due to rheumatism, but the best recognized acquired lesion to produce the mill-wheel murmur is a fistula between a syphilitic aneurysm of the first part of the aortic arch and the pulmonary artery. The following description is of a case of this kind.

\section{Case Report}

History. A factory manager, aged 44 years, was admitted with a history of very good health and good athletic record till two years previously. He then began to notice slight dyspnœe on exertion, which increased gradually till two months before his admission, when he became much more dyspnœic at all times and was in particular subject to acute attacks of dyspnœa at night. A few nights before admission he had severe vomiting, and when admitted he was still trying to make himself vomit and occasionally succeeded in raising a little blood-tinged sputum. He was very nervous and worried, and complained of severe epigastric tightness and discomfort.

Physical examination. A well developed, muscular man, afebrile, orthopnœic, markedly dyspnœic and moderately cyanosed. The neck veins were filled nearly to angle of jaw and pulsated visibly. The heart showed a rather diffuse apical impulse just external to the nipple line in the fifth left space. A loud systolic and diastolic " mill-wheel" murmur was heard all over the præcordium, loudest in the pulmonary area, where it was accompanied by a synchronous palpable thrill. The heart rate was at 116 a minute. The blood pressure was $130 / 50$. The left base showed many râles, and a moderate pleural effusion covered the right base and lower axilla.

The liver was tender and smooth, extending $8 \mathrm{~cm}$. below the right costal margin. Moderate œdema of sacrum, feet and ankles was present.

Investigations. An X-ray of the chest showed much dilatation of the pulmonary artery and conus, and heavy shadows of the pulmonary branches, with some congestion of the lung bases (Fig. 1).

An electrocardiogram showed sinus tachycardia and a tendency to right axis deviation. Lead I showed a good voltage RS and lead III a prominent $Q$ and high $R$ waves. T waves were upright in leads I and II, and showed shallow inversion in lead III. In CR4, the $R$ wave was of low voltage and the $S$ wave deep. A raised S-T segment and shallow inversion of the $T$ wave, also present in this lead, were attributable to myocardial ischæmia resulting from the narrowed coronary ostia (Fig. 2).

The blood Wassermann reaction was positive $(++)$. 


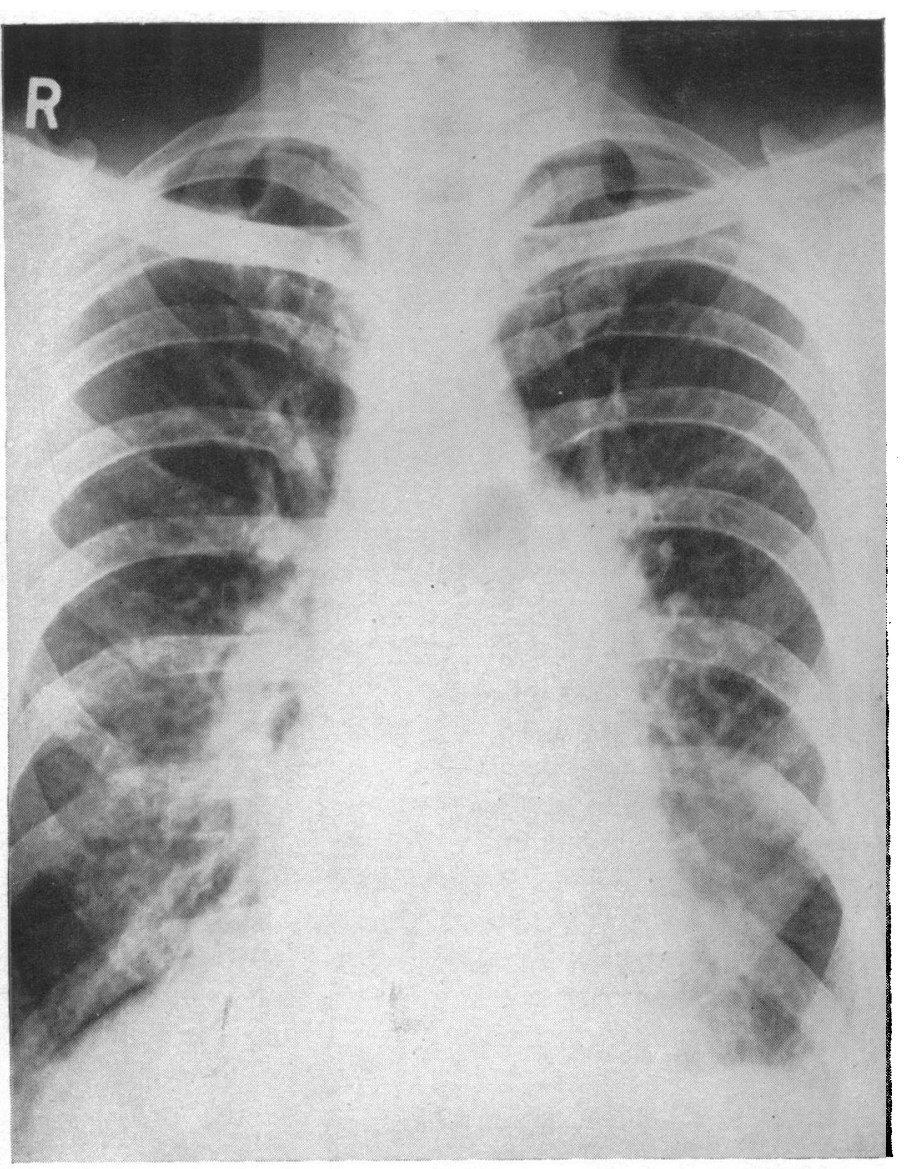

FIG. 1.-Ward Unit X-ray of chest showing no evidence of aortic aneurysm, but considerable distension of the pulmonary artery and congestive hyperæmia of the lungs.

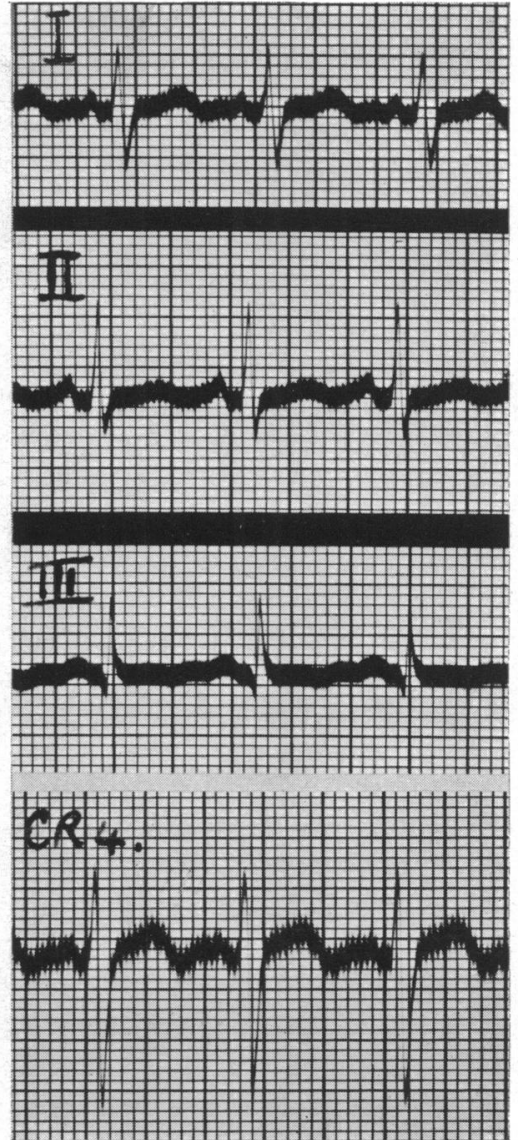

FIG. 2.-Electrocardiogram showing tachycardia and slight tendency to right axis deviation in the standard leads. Chest lead CR4 shows raised S-T and slightly inverted $T$ wave due to the myocardial ischæmia resulting from narrowing of the coronary ostia.

Progress. The patient's condition steadily declined in the next two weeks, and despite gastric lavage he continued to retch. Further accumulation of fluid at the right base and increased dyspnœa necessitated aspiration of two pints of blood-stained pleural fluid, but he remained very ill and the neck veins continued to show free pulsation. Increasing weakness and drowsiness preceded his death on the thirteenth day in hospital.

Necropsy (Dr. J. L. Hamilton Paterson). Heart enlarged, with hypertrophy of both ventricles; valves competent; pericardium normal; myocardium firm and reddish in colour. The ascending part of the aorta showed a saccular aneurysm which anteriorly had pressed against the pulmonary artery. Here the sac wall had been thinned with resulting perforation into the pulmonary artery immediately above the semilunar (tricuspid) valve. The aneurysm showed much irregular thickening and fibrosis of the aortic wall, suggestive of syphilitic nature; the coronary ostia, particularly the left, were narrowed by the disease. The perforation was $6 \mathrm{~mm}$. in diameter and roughly triangular in shape. All the lobes of the lung showed an intense œdema. The liver showed advanced nutmeg change with early nodular hypertrophy.

\section{Discussion}

The rupture of syphilitic aneurysms is usually into the main pulmonary trunk, as in the case just described, but one case of two reported by Schattenburg and Harris (1943) ruptured into the 
left pulmonary artery. These writers estimated that upwards of sixty cases had been described by 1943, the first by Wells in 1812 (quoted by Peacock), and the first full clinical description by Hope in 1839. Wade (1861) made the first clinical ante-mortem diagnosis, and in 1868 there were two excellent clinical accounts of cases by Murchison and by Peacock, the latter also giving an up-to-date summary of thirty-three cases of thoracic aortic aneurysms perforating the cavities of the heart and of the adjacent great vessels. Eighteen of these were from the sinuses of Valsalva and twelve from the first part of the aortic arch. In his case Roberts (1869) was struck by the superficiality of the murmur thus foreshadowing a similar observation made by Maude Abbott (1937) on the murmur of aortic septal defect.

A rarer mode of rupture of an aortic aneurysm is into one of the larger thoracic viens, and Danaray's (1949) account of a Chinese labourer who suffered this accident reveals its catastrophic nature: within twenty-seven hours of sudden severe pain across the chest, the patient had died after developing severe dyspnœa, cyanosis, engorgement of neck veins and a swollen neck; he showed a widespread præcordial machinery murmur. A similar type of murmur of congenital origin is described by Biörck and Crafoord (1947), who found at operation an aneurysm on an aberrant coronary artery opening into the main pulmonary artery.

The close apposition of pulmonary artery and aorta may cause a quite small syphilitic aneurysm to perforate into the pulmonary artery as a result of pressure erosion. This was so in our case, in two of Peacock's cases, and also in Roberts' case, where the aneurysm was " half the size of a walnut shell." An erosive opening appears usual, but Peacock quotes examples of aneurysms that " lacerated" into the pulmonary artery with correspondingly worse prognosis. Osler and McCrea (1936) state that rupture may cause instantaneous death, but, on the other hand, death may not follow perforation for twenty-one months (White et al., 1941). Porter (1942), after observing three cases, considered that the time of survival depended both on the size of the fistulous opening and on the amount of associated cardiovascular disease. Our case emphasises the fact found in others previously reported that perforation may not be accompanied by præcordial pain; sensations of " chill" and increasing dyspnœa are often the main initial symptoms. It also shows the importance of catastrophic cardiac failure and a positive Wassermann reaction in making full assessment of a case where a mill-wheel murmur is present, for in it neither radiography nor electrocardiography gave distinctive findings.

\section{REFERENCES}

Abbott, M. (1937). Nelson's Loose Leaf Medicine, 4, 269.

Biörck, G., and Crafoord, C. (1947). Thorax, 2, 65.

Dadds, J. H., and Hoyle, C. (1949). Brit. Heart J., 11, 390.

Danaray, T. J. (1949). Brit. med. J., 1, 1124.

Hope, J. (1839). A Treatise on Disease of the Heart and Great Vessels. 3rd ed. London, 439.

Morgan Jones, A., and Langley, F. A. (1949). Brit. Heart J., 11, 325.

Murchison, C. (1868). Trans. Path. Soc. London, 19, 190.

Osler, W., and McCrea, S. (1936). The Principles and Practice of Medicine. 10th ed., New York, 873.

Peacock, T. B. (1868). Trans. Path. Soc. London, 19, 111.

Porter, W. B. (1942). Amer. Heart J., 23, 468.

Roberts, W. (1869). Brit. med. J., 1, 421.

Schattenburgh, H. J., and Harris, W. H. (1943). Amer Heart J., 25. 512.

Wade, W. F. (1861). Med. Chir. Trans. London, 44, 211.

White, P. D., Chamberlain, F. L., and Kelson, S.R. (1941). Ann. intern. Med., 15, 589. 